\title{
THREE-LAYER ANALYTICAL SOLUTION FOR WAVE ATTENUATION BY SUSPENDED AND NONSUSPENDED VEGETATION CANOPY
}

\author{
Long-Huan Zhu' ${ }^{1}$ and Qing-Ping Zou*
}

\begin{abstract}
A generalized three-layer analytical solution for the wave attenuation by suspended and non-suspended vegetation canopy is developed in this study. The analytical solution reduces to the two-layer analytical solution by Kobayashi et al. (1993) for the non-suspended vegetation canopy rooted at the sea bed. The present theory is verified using laboratory experiments and field observations of a suspended and non-suspended as well as emerged and submerged vegetation canopy. The wave attenuation increase with the drag coefficient, blade diameter and length, canopy density and length, the elevation of the bottom of the canopy and the incident wave height. The influences of wave frequency and water depth on wave attenuation are more complex. They affect the wave attenuation mainly by changing the wave flow velocity encountered by the vegetation canopy. As a result, the canopy vertical position has significant impact on the relationship between the wave attenuation and wave frequency.
\end{abstract}

Keywords: wave attenuation; suspended vegetation canopy; vegetation; analytical solution; wave and vegetation interaction

\section{INTRODUCTION}

Aquatic canopy can serve as natural breakwaters due to its effects on wave attenuation. The vegetation canopy may be categorized as submerged or emerged, and rooted or suspended based on the its height relative to the water depth and vertical location in the water column (Plew, 2011; Huai et al., 2012; Chen et al., 2016).

During the past decades, most researchers focused on the wave attenuation by the submerged and emerged vegetation canopy rooted at the bottom, using field observation (e.g., Knutson et al., 1982; Möller et al., 1999; Bradley and Hauser, 2009; and Horstman et al., 2014), lab experiments (e.g., Fonseca and Cahalan, 1992; Augustin et al., 2009; Stratigaki et al., 2011; Koftis et al., 2013; Anderson and Smith, 2014; Hu et al., 2014; Ozeren et al., 2014; Wu and Cox, 2015; Wang et al., 2016), numerical methods (e.g., Li and Xie, 2011; Ma et al., 2013; Maza et al., 2013; Marsooli and Wu, 2014; Zhu and Chen, 2015; Chakrabarti et al., 2016), and analytical study.

For the analytical studies, Dalrymple et al. (1984) developed the analytical expression of the regular wave height reduction over vegetation based on the wave energy conservation equation. On the other hand, Kobayashi et al. (1993) obtained a similar solution by solving the momentum equations assuming that wave height decays exponentially through the vegetation canopy. These two models have been used widely by the other researchers. Dalrymple et al.'s (1984) formulation was extended for random waves by Mendez and Losada (2004) and for wave and current conditions by Losada et al. (2016) while Kobayashi et al.'s (1993) solution was extended for flexible vegetation by Dubi and Torum (1994) and for wave and current conditions by Otta et al., (2004). Recently, Chen and Zhao (2012) and Liu et al. (2015) proposed an analytical model for submerged and emergent vegetation canopy.

However, suspended vegetation canopy has received little attention in comparison to the submerged and emerged vegetation canopy rooted at the bottom. Only recently did researchers start to pay attention to the wave attenuation by the suspended canopy (Plew 2005; Chen et al. 2016). Theoretical work for the wave attenuation through suspended vegetation canopy is scarce in literature.

In this study, a generalized three-layer analytical solution is obtained for wave attenuation through all these types of canopies in present paper. The theory is validated using the experiment by Ozeren et al. (2014) and field observations by Plew et al. (2005). The wave and vegetation parameters that influence the capacity of the canopy to attenuate the wave are investigated using the analytical solution.

\section{METHODOLOGY}

Kobayashi et al. (1993) developed a 2-layer model to solve 2-D problem of small-amplitude waves propagating over submerged rigid vegetation rooted at the bottom. This 2-layer model is formulated by using the continuity and linearized momentum equations for the regions above and within vegetation.

\footnotetext{
${ }^{1}$ Department of Civil and Environmental Engineering, University of Maine, Orono, Maine, 04469, USA

* Corresponding author: qingping.zou@maine.edu
} 
The effect of vegetation is considered as drag forces adding to the momentum equations within vegetated region. An analytical solution is obtained on the assumption that wave height decays exponentially in horizontal plane within canopy region.

The present study extends the 2-layer model by Kobayashi et al. (1993) to a generalized 3-layer model for suspended vegetation canopy at any position in the water column, illustrated in Fig. 1, in which the horizontal coordinate $x$ is positive in the direction of wave propagation, the vertical coordinate $z$ is positive upward, with $z=0$ at the still water level, $d_{1}$ denotes the distance from the still water surface to the top of the canopy, $d_{2}$ denotes the height of canopy and $d_{3}$ denotes elevation of the bottom of the canopy bottom relative to seabed. When $d_{3}=0$ and $d_{1} \neq 0$, it is the submerged canopy rooted at the bottom; when $d_{3}=0$ and $d_{1}=0$, it is the emerged canopy rooted at the bottom and when $d_{3} \neq 0$, it is the suspended canopy case (floating on surface when $d_{1}=0$ and suspended in water when $\left.d_{1} \neq 0\right)$. The sea bed located at $z=-\left(d_{1}+d_{2}+d_{3}\right)$ is assumed to be horizontal.

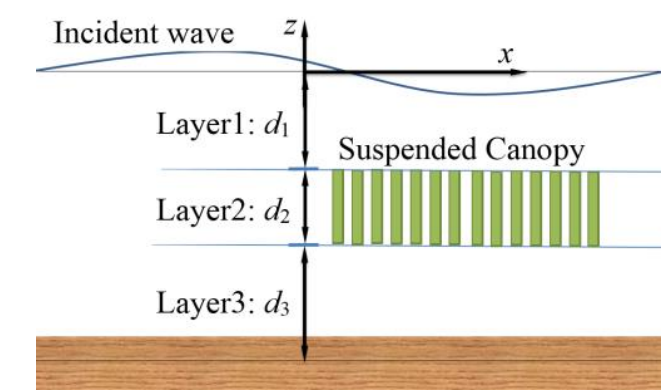

Figure 1. Definition sketch of variables and coordinate system for the three-layer analytical model of waves propagating over a vegetation canopy.

The continuity and linearized momentum equations are given by

$$
\begin{gathered}
\nabla \cdot \vec{u}_{1}=0 \\
\frac{\partial \vec{u}_{1}}{\partial t}=-\frac{1}{\rho} \nabla p_{1}
\end{gathered}
$$

for the layer 1 at the surface;

$$
\begin{gathered}
\nabla \cdot \vec{u}_{2}=0 \\
\frac{\partial \vec{u}_{2}}{\partial t}=-\frac{1}{\rho} \nabla p_{2}-\frac{1}{\rho} \vec{F}
\end{gathered}
$$

for the layer 2 in the middle of the water column where the canopy is; and

$$
\begin{gathered}
\nabla \cdot \vec{u}_{3}=0 \\
\frac{\partial \vec{u}_{3}}{\partial t}=-\frac{1}{\rho} \nabla p_{3}
\end{gathered}
$$

for the layer 3 at the bottom, where $t$ is time. $\vec{u}_{n}=\left(u_{n}, w_{n}\right)$ is the water particle velocity vector with horizontal and vertical components, $u_{n}$ and $w_{n}$, in the layer $n(n=1,2,3) . p_{n}$ is the dynamic pressure due to wave action in the layer $n$. The total pressure should include both the dynamic pressure $p_{n}$ and the hydrostatic pressure $-\rho g z$ below still water line. $\rho$ is the water density and $g$ is the gravitational acceleration. $\vec{F}=\left(F_{x}, F_{z}\right)$ is the drag force per unit volume with the horizontal and vertical components $F_{x}$ and $F_{z}$. We treat each blade in the canopy as a rigid vertical cylinder with a small diameter and apply the Morison equation to obtain the drag force exerted on the canopy per unit volume: 


$$
\begin{gathered}
F_{x}=\frac{1}{2} \rho C_{D} b N\left|u_{2}\right| u_{2} \\
F_{z}=0
\end{gathered}
$$

in which $C_{D}$ is the drag coefficient for a representative blade in the suspended canopy, $b$ is the projected area per unit height of each blade normal to the horizontal velocity, $N$ is the number of blades per unit horizontal area.

The linearized boundary and matching conditions at the free surface:

$$
\begin{aligned}
& w_{1}=\frac{\partial \eta_{1}}{\partial t} \quad \text { at } \quad z=0, \\
& p_{1}=\rho g \eta_{1} \quad \text { at } \quad z=0,
\end{aligned}
$$

at the interface between layer 1 and layer 2:

$$
\begin{gathered}
w_{2}=\frac{\partial \eta_{2}}{\partial t} \quad \text { at } \quad z=-d_{1}, \\
p_{2}=p_{1} \quad \text { at } \quad z=-d_{1}, \\
w_{2}=w_{1} \quad \text { at } \quad z=-d_{1},
\end{gathered}
$$

at the interface between layer 2 and layer 3:

$$
\begin{gathered}
w_{3}=\frac{\partial \eta_{3}}{\partial t} \quad \text { at } \quad z=-\left(d_{1}+d_{2}\right), \\
p_{3}=p_{2} \quad \text { at } \quad z=-\left(d_{1}+d_{2}\right) \\
w_{3}=w_{2} \quad \text { at } \quad z=-\left(d_{1}+d_{2}\right)
\end{gathered}
$$

at the bottom:

$$
w_{3}=0 \text { at } z=-\left(d_{1}+d_{2}+d_{3}\right),
$$

where $\eta_{1}$ denotes the elevation of free surface above still water line, $\eta_{2}$ denotes the vertical displacement of the interface between layer 1 and layer 2 , and $\eta_{3}$ denotes the vertical displacement of the interface between layer 2 and layer 3 . The horizontal velocities $u_{1}, u_{2}$, and $u_{3}$ do not match at the interfaces because the horizontal momentum equation changes abruptly from Eq. 2 to Eq. 4 and from Eq. 4 to Eq. 6 in which $F x$ given by Eq. 7 is nonzero. Thus, the shear stress at the interfaces would need to be considered in Eq. 2, Eq. 4, and Eq. 6 to match $u_{1} u_{2}$, and $u_{3}$.

We assume an exponential decay in wave height and the wave height at distance $x$ into the canopy is related to the incident wave height $H_{0}$ at $x=0$ by

$$
H=H_{0} e^{-k_{v} x}
$$

where $k_{v}$ is the exponential decay coefficient $\left(m^{-1}\right)$. Accordingly, the free surface elevation $\eta_{1}$ may be expressed as

$$
\eta_{1}=\frac{H_{0}}{2} e^{-k_{v} x} \cos (k x-\sigma t)
$$

where $k$ is the wave number and $\sigma$ is the angular frequency. 
Assuming weak damping and relatively small drag force, the governing equations (Eq. 1-6) can be solved with the boundary conditions (Eq. 9-17). We obtain the generalized analytical solution of the exponential decay coefficient $k_{v}$ for a vegetation canopy at any position in the vertical direction

$$
k_{v}=k \frac{1}{9 \pi} C_{D} b N H_{0} \frac{\sinh \left[3 k\left(d_{2}+d_{3}\right)\right]-\sinh \left(3 k d_{3}\right)+9 \sinh \left[k\left(d_{2}+d_{3}\right)\right]-9 \sinh \left(k d_{3}\right)}{\sinh (k h)[2 k h+\sinh (2 k h)]}
$$

in which, $h$ is the total water depth, $h=d_{1}+d_{2}+d_{3}$. When $d_{3}=0$, Eq. 20 reduces to the 2-layer solution by Kobayashi et al. (1993) for a vegetation canopy rooted at the bottom

$$
k_{v}=k \frac{1}{9 \pi} C_{D} b N H_{0} \frac{\sinh \left(3 k d_{2}\right)+9 \sinh \left(k d_{2}\right)}{\sinh (k h)[2 k h+\sinh (2 k h)]}
$$

The wave attenuation through the vegetation canopy can be evaluated using the wave height transmission coefficient, $T_{H}$, which is the ratio of transmitted wave height $H_{t}$ to the incident wave height $H_{0}$

$$
T_{H}=\frac{H_{t}}{H_{0}}=e^{-k_{v} L_{v}}
$$

where $L_{v}$ is the length of the suspended vegetation canopy. Similarly, the wave energy transmission coefficient, $T_{E}$, the ratio of the transmitted wave energy to the incident wave energy is equal to the square of wave height transmission coefficient

$$
T_{E}=\frac{H_{t}^{2}}{H_{0}^{2}}=e^{-2 k_{v} L_{v}}=T_{H}^{2}
$$

\section{MODEL VALIDATION}

\section{Wave propagation through a submerged and emergent canopy}

The 3-layer analytical solution is validated against the laboratory experiments by Ozeren et al. (2014) for regular waves propagating over submerged and emerged vegetation canopy. The wave height is $0.06 \mathrm{~m}$, the wave period is $1 \mathrm{~s}$, and the water depth is $0.5 \mathrm{~m}$. The diameter of the rigid model vegetation is $9.4 \mathrm{~mm}$, the vegetation density $N$ is $350 \mathrm{~m}^{-2}$, and the length of the canopy $L_{v}$ is $3.66 \mathrm{~m}$. For the submerged case, the model vegetation stem height $h_{v}$ is $0.48 \mathrm{~m}$ and the drag coefficient $C_{D}$ is 1.97 , while $h_{v}$ is $0.63 \mathrm{~m}$ (larger than the water depth) and $C_{D}$ is 2.49 for the emerged case.

The comparison between the present model and the experiment data is shown in Fig. 2 and Fig. 3 for submerged and emerged canopy respectively. It can be seen that the analytical solution of the wave height agrees well with the measurements by the wave gauges.

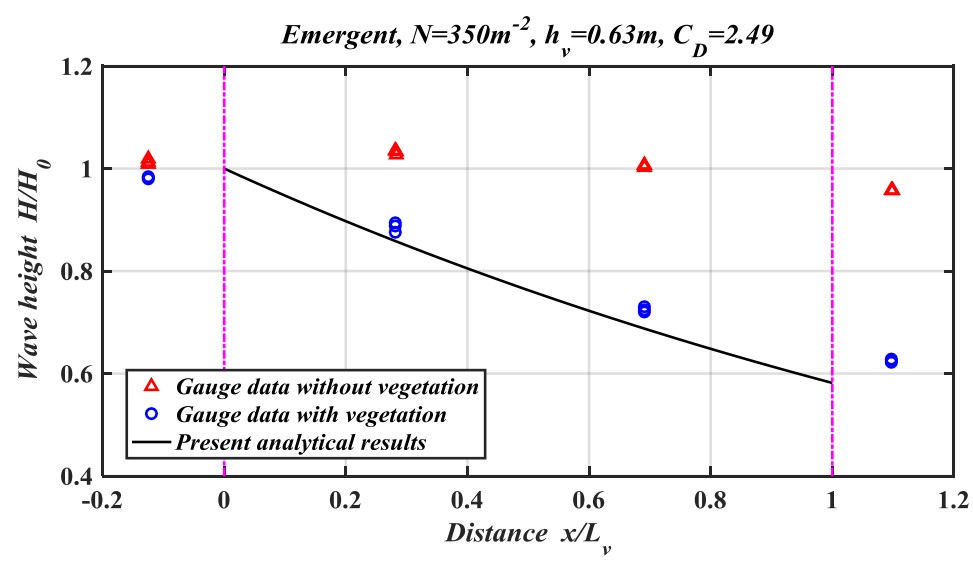

Figure 2. Wave transmission (ratio of the local wave height $H$ to the incident wave height $\mathrm{H}_{0}$ ) as a function of the distance into the canopy normalized from the total length of the canopy $L_{v}$ : triangles denote the gauge data without vegetation; circles denote the gauge data with vegetation; solid line denotes the present analytical solution. Dash-dotted lines denote the edges of vegetation canopy. 


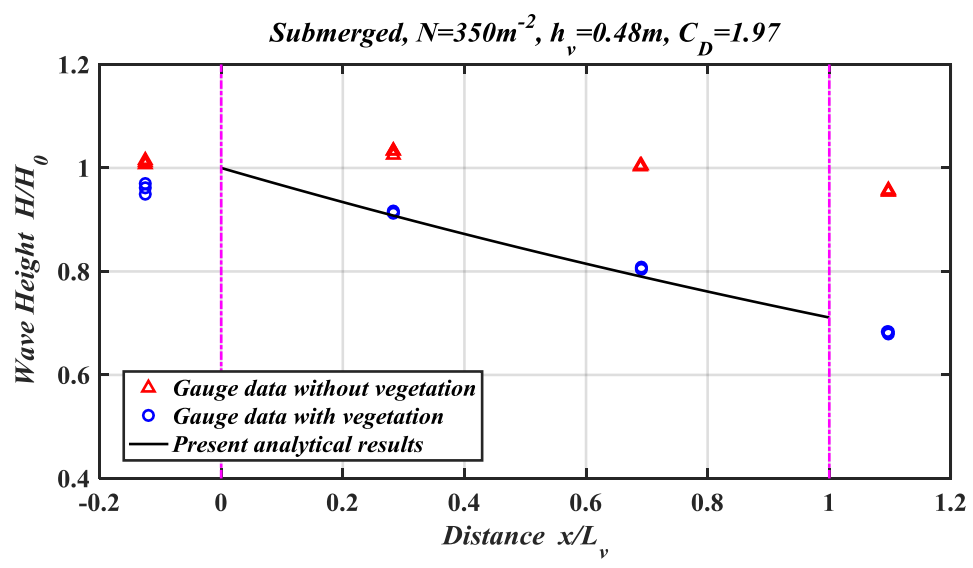

Figure 3. Same as Fig. 2 except for the emerged vegetation canopy.

\section{Wave propagation through a suspended canopy}

The present analytical solution is validated using the field observations for a suspended canopy by Plew et al (2005). During this field experiment, the random wave with a peak wave period of $12.5 \mathrm{~s}$ propagates through a mussel farm with a size of $2450 \mathrm{~m}$ by $650 \mathrm{~m}$, at a water depth varying from 9 to $12 \mathrm{~m}$ and approximately $2.5 \mathrm{~km}$ away from the shoreline, which can be considered as a suspended canopy. The significant wave height varies from averaging $0.063 \mathrm{~m}$ to a peak value of $0.25 \mathrm{~m}$ at the offshore side of the farm during the field experiment. We use the same incident wave height of $0.1 \mathrm{~m}$, $0.2 \mathrm{~m}$ and $0.5 \mathrm{~m}$ as Plew et al. (2005). The energy transmission coefficient $T_{E}$ is calculated at a distance of $650 \mathrm{~m}$ into the canopy. The key vegetation parameters are: the dropper length $d_{2}=8 \mathrm{~m}$, dropper diameter $b=0.14 \mathrm{~m}$, water depth is $h=10 \mathrm{~m}, C_{D}=1.7$ and density $N=0.06 \mathrm{~m}^{-2}$.

Fig. 4 demonstrate that the present analytical solution is in an improved agreement with the field observations in comparison with the model predictions (thick lines) by Plew et al (2005).

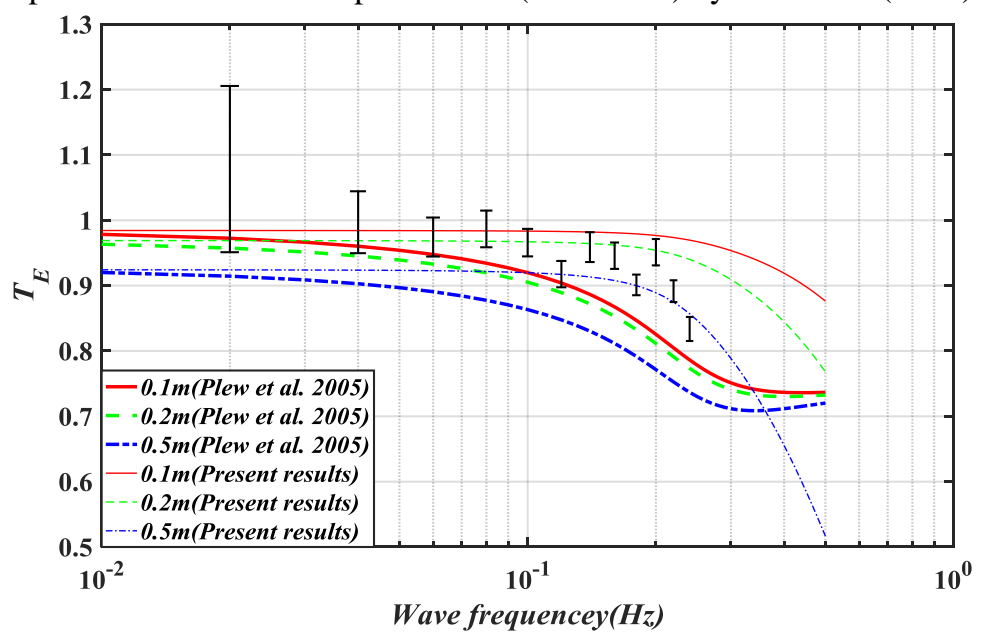

Figure 4 Wave energy transmission coefficient $T_{E}$ (same as ETR by Plew et al. (2005)) vs. wave frequency. The incident wave height is $0.1 \mathrm{~m}, 0.2 \mathrm{~m}$ and $0.5 \mathrm{~m}$ given in the legend. The vertical bars denote the $95 \%$ confidence interval of the field observations of energy transmission coefficient. The thin lines represent the present analytical solution and the thick lines represent the model predictions by Plew et al. (2005).

\section{MODEL RESULTS AND DISCUSSIONS}

The wave attenuation is quantified by the wave height transmission coefficient $T_{H}$, which is the exponential function of the product of decay coefficient $k_{v}$ and the length of the canopy $L_{v}$, as shown in Eq. 22. Obviously, the larger canopy with higher decay coefficient $k_{v}$ attenuate more wave energy. According to Eq. 20, the decay coefficient $k_{v}$ is linearly proportional to the drag coefficient $C_{D}$, each blade diameter $b$, canopy density $N$, and the incident wave height $H_{0}$. It also increases with increasing blade length $d_{2}$ and the elevation of the canopy $d_{3}$. But $k_{v}$ is a non-monotonic function of the wave number $k$ and water depth $h$ since $d_{2}+d_{3}=h-d_{1}$. $k$ is a function of water depth $h$ for a given wave period, so that both the numerator and the denominator include $h$ in Eq. 20. We will next discuss about the influence of these parameters. 
The wave attenuation by a vegetation canopy at different elevations including that floating on the surface, suspended in the water column, and rooted at bottom, is examined following the experiments by Ozeren et al. (2014). The vegetation stem height $d_{2}=0.2 \mathrm{~m}$.

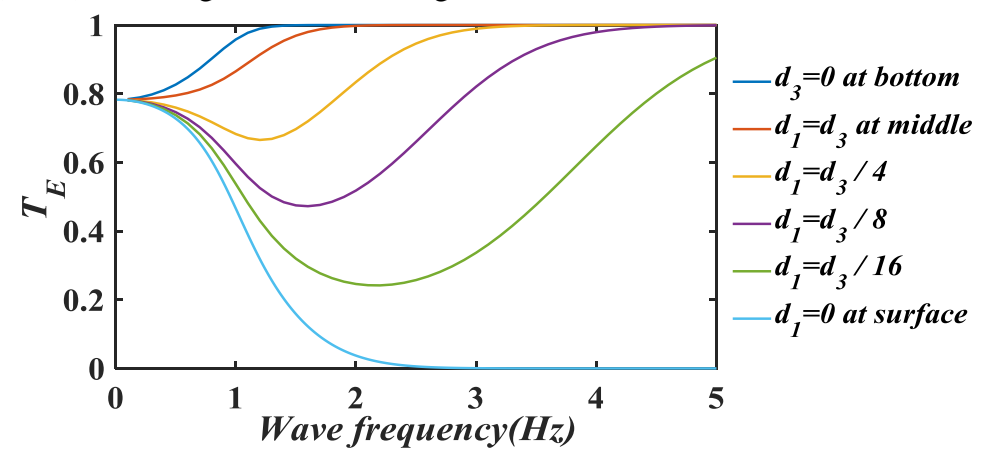

Figure 5. Wave energy transmission coefficient $T_{E}$ vs. wave frequency for an aquatic canopy at different vertical locations. $d_{3}=0$ indicate the canopy rooted at bottom, $d_{1}=0$ denotes canopy floating at the water surface and other values of $d_{1}$ represents the canopy suspended in the middle of the water column.

Comparison in Fig. 5 indicates that the wave energy transmission coefficient $T_{E}$ by the canopy at different locations are nearly the same at low frequency. However, as wave frequency increases, wave attenuation by canopies at different locations behaves differently. With increasing wave frequency, $T_{E}$ decreases to 0 when the canopy is floating on the surface while increases towards 1 when the canopy is situated at the bottom. It is also found that when the canopy is located at the upper half of the water column $\left(d_{1}<d_{3}\right), T_{E}$ first decreases and then increases to 1 . The frequency range for $T_{E}$ less than 0.6 extends as well when the canopy moves upwards, indicating that the canopy can effectively dissipate wave energy for a wider frequency range as it moves upwards.

\section{CONCLUSIONS}

In this paper, a 3-layer analytical model has been developed to study wave attenuation by vegetation canopy at different locations in the water column. The analytical solution is in good agreement with both laboratory and field observations.

The major parameters that influence the wave attenuation over a suspended canopy has been discussed. The wave attenuation increase with the drag coefficient $C_{D}$, each blade diameter $b$, each blade length $d_{2}$, canopy density $N$, canopy length $L_{v}$, the elevation of the bottom of the canopy $d_{3}$ and the incident wave height $H_{0}$. The influence of wave frequency and water depth on the wave attenuation is more complex. They affect the wave attenuation mainly by changing the wave flow velocity encountered by the vegetation canopy, which is dependent on the vertical distance from the free surface normalized by the wave length (Zou et al., 2003). As a result, the canopy vertical position has significant impact on the relationship between the wave attenuation and wave frequency. The wave attenuation increases with the flow velocity encountered by the canopy. At relatively low frequency or over a relatively shallow water, the water orbital motion remains nearly the same through water column, thus the canopy location has little effect on wave attenuation. At high frequency or over a relatively deeper water, however, the water orbital motion decays rapidly with depth, resulting in decreasing wave attenuation when canopy moves downward towards the bottom.

\section{ACKNOWLEDGMENTS}

This study was supported by National Science Foundation award \#IIA-1355457 to Maine EPSCoR at the University of Maine.

\section{REFERENCES}

Anderson, M.E. and Smith, J.M., 2014. Wave attenuation by flexible, idealized salt marsh vegetation. Coastal Engineering, 83, 82-92.

Augustin, L.N., Irish, J.L. and Lynett, P., 2009. Laboratory and numerical studies of wave damping by emergent and near-emergent wetland vegetation. Coastal Engineering, 56(3), 332-340.

Bradley, K. and Houser, C., 2009. Relative velocity of seagrass blades: Implications for wave attenuation in low-energy environments. Journal of Geophysical Research: Earth Surface, 114(F1). 
Chakrabarti, A., Chen, Q., Smith, H.D. and Liu, D., 2016. Large Eddy Simulation of Unidirectional and Wave Flows through Vegetation. Journal of Engineering Mechanics, 142(8), p.04016048.

Chen, X., Chen, Q., Zhan, J. and Liu, D., 2016. Numerical simulations of wave propagation over a vegetated platform. Coastal Engineering, 110, 64-75.

Chen, Q. and Zhao, H., 2012. Theoretical models for wave energy dissipation caused by vegetation. Journal of Engineering Mechanics, 138(2), 221-229.

Dalrymple, R.A., Kirby, J.T. and Hwang, P.A., 1984. Wave diffraction due to areas of energy dissipation. Journal of Waterway, Port, Coastal, and Ocean Engineering, 110(1), 67-79.

Dubi, A., Torum, A., 1994. Wave damping by kelp vegetation, Proceedings of $24^{\text {th }}$ International Conference on Coastal Engineering, ASCE, 142-156.

Fonseca, M.S. and Cahalan, J.A., 1992. A preliminary evaluation of wave attenuation by four species of seagrass. Estuarine, Coastal and Shelf Science, 35(6), 565-576.

Horstman, E.M., Dohmen-Janssen, C.M., Narra, P.M.F., van den Berg, N.J.F., Siemerink, M. and Hulscher, S.J.M.H., 2014. Wave attenuation in mangroves: A quantitative approach to field observations. Coastal engineering, 94, pp.47-62.

Hu, Z., Suzuki, T., Zitman, T., Uittewaal, W. and Stive, M., 2014. Laboratory study on wave dissipation by vegetation in combined current-wave flow. Coastal Engineering, 88, 131-142.

Huai, W., Hu, Y., Zeng, Y. and Han, J., 2012. Velocity distribution for open channel flows with suspended vegetation. Advances in Water Resources, 49, 56-61.

Knutson, P.L., Brochu, R.A., Seelig, W.N. and Inskeep, M., 1982. Wave damping in Spartina alterniflora marshes. Wetlands, 2(1), 87-104.

Kobayashi, N., Raichle, A.W. and Asano, T., 1993. Wave attenuation by vegetation. Journal of waterway, port, coastal, and ocean engineering, 119(1), 30-48.

Koftis, T., Prinos, P. and Stratigaki, V., 2013. Wave damping over artificial Posidonia oceanica meadow: A large-scale experimental study. Coastal Engineering, 73, 71-83.

Li, C.W. and Xie, J.F., 2011. Numerical modeling of free surface flow over submerged and highly flexible vegetation. Advances in Water Resources, 34(4), 468-477

Liu, P.L.F., Chang, C.W., Mei, C.C., Lomonaco, P., Martin, F.L. and Maza, M., 2015. Periodic water waves through an aquatic forest. Coastal Engineering, 96, 100-117.

Losada, I.J., Maza, M. and Lara, J.L., 2016. A new formulation for vegetation-induced damping under combined waves and currents. Coastal Engineering, 107, 1-13.

Ma, G., Kirby, J.T., Su, S.F., Figlus, J. and Shi, F., 2013. Numerical study of turbulence and wave damping induced by vegetation canopies. Coastal Engineering, 80, 68-78.

Marsooli, R. and Wu, W., 2014. Numerical investigation of wave attenuation by vegetation using a 3D RANS model. Advances in Water Resources, 74, 245-257.

Maza, M., Lara, J.L. and Losada, I.J., 2013. A coupled model of submerged vegetation under oscillatory flow using Navier-Stokes equations. Coastal Engineering, 80, 16-34.

Mendez, F.J. and Losada, I.J., 2004. An empirical model to estimate the propagation of random breaking and nonbreaking waves over vegetation fields. Coastal Engineering, 51(2), 103-118.

Möller, I., Spencer, T., French, J.R., Leggett, D.J. and Dixon, M., 1999. Wave transformation over salt marshes: a field and numerical modelling study from North Norfolk, England. Estuarine, Coastal and Shelf Science, 49(3), 411-426.

Ota, T., Kobayashi, N. and Kirby, J.T., 2005. Wave and current interactions with vegetation. Proceedings of $29^{\text {th }}$ International Conference, ASCE, 508-520.

Ozeren, Y., Wren, D.G. and Wu, W., 2014. Experimental investigation of wave attenuation through model and live vegetation. Journal of Waterway, Port, Coastal, and Ocean Engineering, 140(5), p.04014019.

Plew, D.R., Stevens, C.L., Spigel, R.H. and Hartstein, N.D., 2005. Hydrodynamic implications of large offshore mussel farms. IEEE Journal of Oceanic Engineering, 30(1), 95-108.

Plew, D.R., 2011. Depth-averaged drag coefficient for modeling flow through suspended canopies. Journal of Hydraulic Engineering, 137(2), 234-247.

Stratigaki, V., Manca, E., Prinos, P., Losada, I.J., Lara, J.L., Sclavo, M., Amos, C.L., Cáceres, I. and Sánchez-Arcilla, A., 2011. Large-scale experiments on wave propagation over Posidonia oceanica. Journal of Hydraulic Research, 49(sup1), 31-43.

Wang, Q., Guo, X.Y., Wang, B.L., Fang, Y.L. and Liu, H., 2016. Experimental measurements of solitary wave attenuation over shallow and intermediate submerged canopy. China Ocean Engineering, 30(3), 375-392. 
Wu, W.C. and Cox, D.T., 2015. Effects of wave steepness and relative water depth on wave attenuation by emergent vegetation. Estuarine, Coastal and Shelf Science, 164, pp.443-450.

Zhu, L. and Chen, Q., 2015. Numerical modeling of surface waves over submerged flexible vegetation. Journal of Engineering Mechanics, 141(8), A4015001.

Zou, Q.-P., Hay, A.E. and Bowen, A.J., 2003. Vertical structure of surface gravity waves propagating over a sloping seabed: Theory and field measurements. Journal of Geophysical Research: Oceans, 108(C8), Art. No. 3265. (doi:10.1029/2002JC001432). 